\section{AN INTRODUCTION TO CLINICAL SURGERY}

By Charles F. M. Saint, Professor of Surgery, University of Cape Town. Published for the Post-Graduate Press by The African Bookman, Cape Town, I 945 .

This book contains the substance of the tutorials given each year by Professor Saint to his Surgical Dressers. It is based on his small book, Surgical Note-taking.

Its 289 pages of close type contain an enormous amount of material, obviously resulting from a wide experience, and cover very many points of practical importance. Its scheme is to consider the commonly encountered surgical conditions in turn, discussing for each the importance of the history and development of the condition, the family history, physical signs and laboratory tests. From the data so acquired the student is shown how to arrive at a diagnosis either by the positive method of direct induction or more rarely, when necessary, by the negative method of ruling out the more unlikely.

Throughout the book Professor Saint lays the greatest emphasis on careful history-taking together with a thorough examination of the patient, and his detailed discussion of the exact significance of the physical signs is most stimulating. Each section shows the results of the author's careful observation and of his care in making the student think things out for himself, as for instance in making full use of the physical signs before looking for the results of laboratory tests, though these are given their due importance. His chapter on Peripheral Vascular Disease is particularly noteworthy.

Professor Saint's teaching is dogmatic, as teaching undoubtedly should be, but it is bound therefore to invite criticism. That, in the breast, carcinoma follows chronic irritation, that Paget's disease of the nipple is likely to go onto a superficial epithelioma, and that a blood-stained discharge expressed from all parts of the breast requires, in a large proportion of cases, no interference, are all subjects on which other views are held.

For the average student in the ward as he emerges, often painfully, from the cocoon of his childhood, this book is heavy going. Its style is somewhat involved and it is relieved by only two diagrams. For his more assiduous, book-worm fellow, whose cocoon is already shed, Professor Saint is to be congratulated on providing a generous, stimulating and excellently reasoned diet.

\section{REGIONAL ANAESTHESIA}

By H. W. L. MOLesworth, F.R.C.S. 2nd edition, pp. viii, 92. Illustrations 42. Published by $\mathrm{H}$. K. Lewis \& Co., Ltd. 8s. 6d. net.

This book, first published in 1944, owes its second edition to the fact that many copies were destroyed by enemy action and the author has taken the opportunity to make some alterations which experience and constructive criticism rendered desirable.

This book does not aim at being a text-book, but is presented as a record of the author's personal experience.

The subject matter is well set out and the diagrams illustrating the anatomical approach are well done. The photographs on the other hand are poor, and it would have been better if they had been omitted.

The author sets out very clearly the general principles involved in regional anaesthesia and indicates the instruments and drugs required. The methods are described most clearly and aptly illustrated by diagrams. The last chapter is devoted to a short discourse on spinal anaesthesia.

The book is to be recommended to those interested in this field of anaesthesia and is clearly printed and well bound.
CLINICAL DEMONSTRATIONS TO NURSES

By Hamilton Bailey, F.R.C.S. 2nd edition. Published by E. \& S. Livingstone, Edinburgh, 1946. Price Ios. $6 \mathrm{~d}$.

Like all the books written by this author, this little handbook for nurses is excellently produced, both with regard to the descriptive matter and the accompanying illustrations. It should prove a very useful book for any nurse who is at the period of attending the Out-Patients' Departments and needs some guidance on the cases that she may have to deal with. It would appear to me to be a suitable little gift book.

\section{A COMPLETE OUTLINE OF FRACTURES}

By J. Grant Bonnin, M.D., B.S., F.R.C.S. 2nd edition. Published by Wm. Heinemann (Medical Books) Limited, London, 1946. Price 3os.

This textbook on fractures is already well known, but several chapters in the New Edition have been brought up to date and the reader will find most useful the chapter dealing with wounds and compound fractures, in which the author has dealt at length with the newer antiseptics, including penicillin. This book should certainly be in the hands of all resident doctors handling fractures, though its use by the senior members of the profession may be somewhat restricted by a certain incompleteness on difficult points of treatment; the reviewer had a need recently for guidance as to a particular line of treatment for a difficult fracture, but on referring to the book found the advice given was merely to operate. The diction also is rather involved at times and needs careful following. The X-rays, which are numerous, would perhaps have been reproduced better if done on a shiny surface, but these defects are remedied by the excellent line drawings which amply illustrate the book.

NEW AND FORTHCOMING PUBLICATIONS, 1946 By H. K. LewIS \& Co. LTD.

Just Published. HOMO SAPIENS: AND THE PEACE PROBLEM. By G. H. MONRAD-KROHN, M.D.(Oslo), F.R.C.P. (Lond.) Crown 4to. 2s. 6d. net.

CARDIOVASCULAR DISEASE IN GENERAL PRACTICE By TERENCE EAST, M.D., D.M.(Oxon.), F.R.C.P.(Lond.) Second Edition. With Illustrations. Demy 8vo. 12s. 6d. net.

AN INTRODUCTION TO CLINICAL SURGERY. Surgical Wherefores and Therefores. A Reasoned Explanation of Surgical Note-Taking. By ChARLES F. M. SAINT, C.B.E., M.S., F.R.C.S. 25s. net. Med. 8vo.

OCCUPATIONAL THERAPY FOR THE LIMBLESS. By Phyllis LytTleton, C.S.P., A.O.T. Crown 8vo. Profusely illustrated. 3s. net.

THEORY AND PRACTICE OF NURSING. By M. A. GullaN. Fifth Edition. With illustrations. Demy 8vo. 12s. 6d. net.

SANITARY SCIENCE NOTES. By HARRY HILL, F.R.San.I. and ERNEST DoDSWORTH, M.R.San.I. F'cap. 8vo. 7s. 6d. net.

THE SANITARY INSPECTOR'S HANDBOOK. By H. H. CLAY, F.R.San.I., F.I.S.E. Fifth Edition, Revised and Enlarged. 97 Illustrations.' Demy 8vo. 18s. net. Second Reprint, 1946.

Ready June. SQUINT AND CONVERGENCE. By N. A. StUTterheim, M.D.(Rand). Crown 4to. With Illustrations. 15s. net.

HANDBOOK FOR ASSISTANT MEDICAL OFFICERS OF HEALTH ON CHILD WELFARE AND SCHOOL MEDICAL WORK. By F. J. G. LishMAN, M.D., M.B., B.S., D.P.H., D.L.O. Second Edition. Demy 8vo. Paper Boards.

ANALECTA PSYCHIATRICA. By J. R. WhitWELl, M.B. Crown 8vo. 16s. net. 